\title{
Search Engine Strategy Report Case Study University of Dundee
}

\author{
Nawaf H. Alqahtani ${ }^{1} \&$ Tahani H. Alqahtani ${ }^{2}$ \\ ${ }^{1} \mathrm{Ph}, \mathrm{D}$ candidate in Management, Universiti Kebangsaan Malaysia, Malaysia / Master of International Marketing, \\ Specialization Digital and Social Media Marketing MSc, University of Dundee, UK \\ ${ }^{2} \mathrm{Ph} . \mathrm{D}$ in Management, University of Aberdeen, United Kingdom / Lecturer, College of Economics and \\ Administrative Sciences at Al Imam Mohammad Ibn Saud Islamic University (IMSIU), Riyadh, Kingdom of \\ Saudi Arabia \\ Correspondence: Tahani H. Alqahtani, Ph.D in Management, University of Aberdeen, United Kingdom / \\ Lecturer, College of Economics and Administrative Sciences at Al Imam Mohammad Ibn Saud Islamic \\ University (IMSIU), Riyadh, Kingdom of Saudi Arabia. E-mail: Tahani.h.q@gmail.com
}

Received: November 14, 2021

Accepted: December 3, 2021

Online Published: December 14, 2021

doi:10.5539/ijbm.v17n1p27

URL: https://doi.org/10.5539/ijbm.v17n1p27

\begin{abstract}
It is normal for any organization to have an online attendance on the Internet. With the continued rise of the internet and the growing importance of websites, it has become increasingly difficult for websites trying to reach potential customers/visitors to achieve visibility. Around 4 million new websites appear online every month in Google search engine platform. As a result of this astonishing rise, it has become more difficult for websites to remain visible among the competing sites without using the optimal available search engine tools.

In this study, there is one case study from the United Kingdom that was selected to explore this subject. The research considered how University of Dundee could implement Search Engine Optimization (SEO) and paid listings such as Pay Per Click (PPC) to their website.

The recommendations of this research can be used to guide the marketers how to improve the visibility of their website to the related target audience. In turn allowing marketers to more accurately determine their choice of an optimal search engine marketing strategy.
\end{abstract}

Keywords: search engine, PPC; SEO, digital marketing

\section{Introduction}

Studies have identified the web as searchers' first port of call for locating information. As a result, Search engine strategies have become a significant topic for organizations to consider when improve maintaining and managing their websites.

Sheffield (2020), confirm out that it is necessary for educations and e-commerce websites to be listed in search engine results in order to be visible, visited and ultimately successful. Previous study has pointed that failing to be listed on at least the first two pages of search results will lead to being invisible to $95 \%$ of potential student/consumer. In fact, failure to be listed on the first page of search engine results will mean $38 \%$ of potential student/customers will never see that webpage listing (Verma et al., 2020).

The importance of a search engine is that it assists marketing and advertising departments in putting the right address, or title, in order to become the best answer to customers' questions, or the keywords they write in the search engine.

For example, when someone searches for how a car battery is charged, the best answer to this question might be 'ways to charge a car battery'. Thus, it can assist marketing teams to know how people are looking for their products and how to generate value from digital advertising.

In general, there are two ways a potential user could find any website via Google's search engine (Duggal, 2020). The first is through an 'organic' result listing (on the basis of SEO), and the second is by paid listings such as a PPC listing (Duggal, 2020).

SEO officially started in 2000, and its relentless rise start to take place in 2005, when Google begun updating their algorithm, which they continue to annually (Kasilingam and Thanuja, 2020). Thus, websit owners try to 
make the necessary changes to their site in order to improve their website ranking (Kavitha and Balaji, 2020).

The main objective of SEO is to develop a website's ranking in the search engine results' pages (Kasilingam and Thanuja, 2020). Thus, it is significant for website owners or website developers working in this field to have an essential understanding of search engine-related concepts such as 'crawling' and 'indexing' (Kavitha and Balaji, 2020).

Paid advertising means the product appears when the customer uses keywords, in the search engine, and advertising appears next to the search results (Peter et al., 1999). Paid advertising allows organizations the opportunity to list their websites on the first page of the search results (Tiwari, 2020). Over the last 20 years, paid advertising become a way to generate revenue for search engines (Kasilingam and Thanuja, 2020).However, oganizations will be charged each time a user clicks on the advertised link (Kavitha and Balaji, 2020). According to Kavitha and Balaji (2020), Google Ads can offer to organizations the ability to set how much per click their organizations is spending for the purpose of traffic directly to their website.

This report outlines the search marketing strategy for The University of Dundee School of Business (UDSB) conversion degrees. This report will not explain the different platforms of the search engine. This report has five sections. The first section will focus on Search Engine Optimisation (SEO). Section two looks at Digital Advertising. Section three concerns Digital Marketing Analytics. Section four covers Strategy and Planning of Digital Advertising Analytics for UDSB. The final section provides recommendations and offers a conclusion.

\section{Search Engine Optimisation (SEO)}

\subsection{What Is Search Engine Optimisation and How Does It Work?}

Search Engine optimisation changes the content to make a website more appealing to the search engine and potentially changes the web design to make it more likely that the search engine will display a page higher in the results of search engine searches (Gunjan et al., 2012). It is possible that the average user uses the search engine in order to write the keywords or phrases that they are looking for (Dover and Dafforn, 2011). And the keywords or phrase might by specific or broad. There are three different phrase users might write in the search engine which are:

- Exact match: for example, only the exact phrase (white coffee) (Dover and Dafforn, 2011).

- Phrase match: Phrase containing the exact phrase. For example, (best beans for white coffee) (Dover and Dafforn, 2011).

- Broad match: Phrase containing a widel- understood meaning. For example, (hot caffeinated drink) (Dover and Dafforn, 2011).

The author suggests that UDSB important to have title could be the best answer for all the three different phrases. In order to get UDSB page in the highest rank in Search Engine results (see Figure 1).

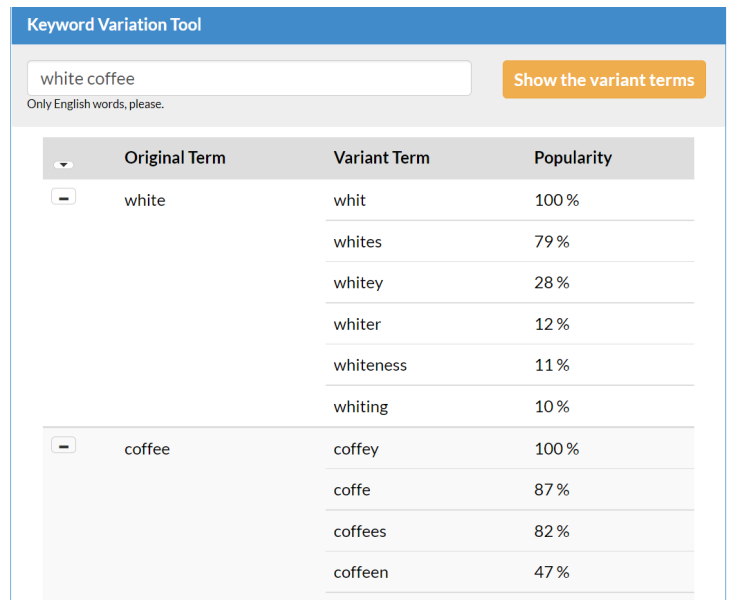

Figure 1. Keyword Variation Tool

Source: karooya, 2019.

However, it is important to understand how search engines work . And how (SEO) illustrate those pages that 
contain links arranged from the top down work (Dover, 2011). The method of Google is to search all the information and links on the Internet, about your query, and arrange them gradually by an algorithm in less than a second (Dover and Dafforn, 2011). There are three main concepts which UDSB must understand to move the rank of UDSB (SEO) to the first link when a user, for example, searches about business schools. These concepts are:

* Crawler: A crawler is a program that visits your web pages; a Crawler reads your page or website and it is selectively indexed by the crawler. In addition, a crawler is interested in reading links and sites that are on your page (Gudivada et al., 2015). Thus, the web-indexing process in the search engine means that the crawler reads all the links in your site. Moreover, crawlers analyse relevance to the topic and the number of people who have linked your page to their pages. The crawler affects the likelihood of your website being high in the search engine process (Gudivada et al., 2015).

* Index: Indexing is a process that occurs before the search, to increase the speed of the search engine and increase the organization of information for the search engine (Dover and Dafforn, 2011). A reverse index is a system by which elements in a database are collected and converted into documents (Dover and Dafforn, 2011). The search engine uses the so-called 'token' to reduce the words to their main meanings and thus reduces the amount of data stored and so it retrieves it faster (Dover and Dafforn, 2011). This approach displays the keywords the user is searching for and fetches relevant links faster (Dover and Dafforn, 2011). Understanding indexing and tokenization will assist UDSB in terms of how search engine indexing works (Gudivada et al., 2015).

- PageRank: PageRank is an algorithm that has obtained a Google patent certificate. It is a process that evaluates the quality of the site or page, through links (Amerland, 2013). The idea is simple: if the links to your site or page are referred from other pages it means that your page is more important and authoritative (Amerland, 2013). Thus, this concept will increase the efficiency of the pages of UDSB by making and encouraging links from external pages in order to raise the ranking of the University of Dundee in search engines (Amerland, 2013).

\subsection{What Factors Affect Search Engine Optimisation?}

A number of diverse factors affect the search process through which we can understand the process of search engine optimisation (Gunjan et al., 2012). However, the basic process that enables the reaching of initial results, in the search process, is to understand the user and how they search, what keywords they use, and how they formulate questions or short phrases (Gunjan et al., 2012). Thus, understanding how users use a search engine can lead the UDSB conversion degrees department to choose the correct title or subjects for the UDSB website (Gunjan et al., 2012). The following factors might impact UDSB's rank on a search engine:

* The frequency of keywords within your page or web scripts. Duplicating these words will increase the impact on the search engine and increase the likelihood of attaining a high rank, so the repetition of keywords used by users is crucial (Spais, 2010).

* The lifetime of a site. Every day, thousands of pages and sites are opened through search engine platforms (Spais, 2010). However, few sites remain for long and long -surviving sites might assist the site in appearing high up on search engine results (Spais, 2010). Those sites with a long history are those that the search engine ranks first when users search (Spais, 2010).

* The number of websites or pages linking to a particular site. The search engine is affected by the number of sites that link to a particular site. The more pages that link to that particular site, the higher the chance that the site might be in the top rank when a search is done (Spais, 2010). Wikipedia is an example of this. Every page in Wikipedia leads you to another page in the same website, and Wikipedia includes thousands of links. This explains why Wikipedia is usually at the top of a search (see Figure 2) (Spais, 2010). 


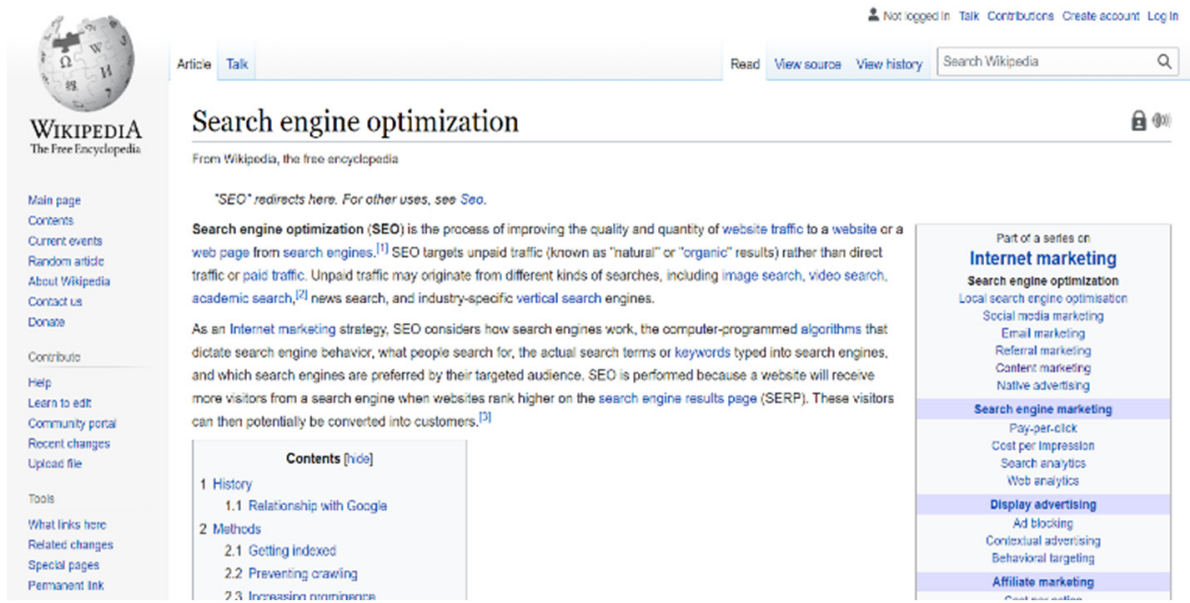

Figure 2. The number of websites or pages linking to a particular site

Source: WIKIPEDIA 2019.

\subsection{Benefits of Search Engine Optimisation for UDSB}

There are a considerable number of benefits of Search Engine Optimisation (Bao et al., 2007). Firstly, millions of searches are done every day from all categories of user keywords (Bao et al., 2007). Understanding this makes it easy to reach a high ranking in a search engine. UDSB must use those words in their subjects and titles in order to achieve a top rank in search results (Bao et al., 2007). Secondly, it is necessary to understand the search engine and how the process allows users to promote a site without paying any additional costs, to understand how a search engine works, and to understand its tools (Bao et al., 2007). Such tools as Crawl, Index and PageRank can lead UDSB to figure in the top ranking search results without paying for advertising (Bao et al., 2007). Finally, Search Engine Optimisation for UDSB can allow users to avoid mistakes when creating pages or subjects. The following factors need to be taken into consideration:

1. Choosing a title is irrelevant. This is one of the most common mistakes (Google, 2019). (UDSB) must choose topics related to a page or text in order to achieve a high-ranking position in the final search results (Google, 2019).

2. The titles of the pages should be short and answer users' questions well (Google, 2019).

3. A common mistake is to use a single title for all the topics on a site (Google, 2019). UDSB must have different and unique topics in order to assist the search engine to separate pages and locate the different titles associated with the keywords that users use (Google, 2019).

\section{Digital Advertising}

\subsection{What is Digital Advertising?}

Digital advertising is advertising through the Internet, to access sites and platforms that are frequented by users (Go and CSD, 2006). Digital advertising is advertising through video or images (Go and CSD, 2006). Digital advertising has become a space to attract consumers more precisely (Go and CSD, 2006). Digital media is becoming more accessible to users and building a mass base through digital advertising is possible (Go and CSD, 2006). Moreover, digital advertising might create a well-known brand (Go and CSD, 2006).

\subsection{How Many Types of Digital Advertising Are There?}

Firstly, Display advertising, also known as Native Advertising, is a video, with images, animation or phrases with backgrounds (Dickey \& Lewis, 2012). It can be seen in the most famous sites where advertising is used, namely Facebook (see Figure 3) (Dickey \& Lewis, 2012). 


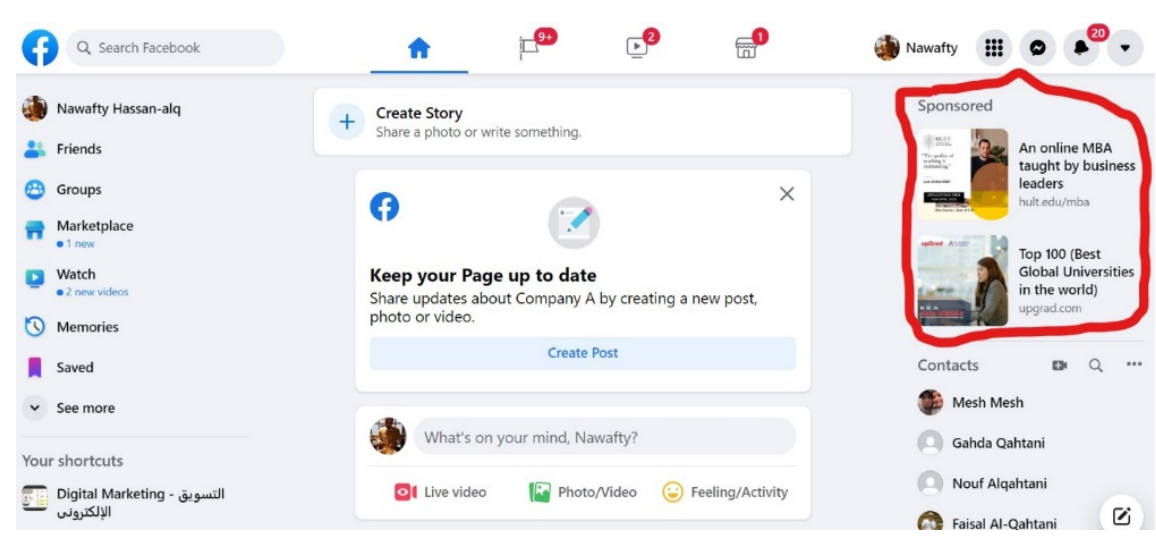

Figure 3. Display advertising

Source: Facebook 20190.

Secondly, one type of Digital Advertising is Pay Per Click (PPC) ads, a marketing process that is done by each user clicking on an ad that then costs the advertiser. For example, an advertiser will pay $£ 5$ per click and, at the end of the month, if 20 users click on that ad, the advertiser will pay $£ 100$ (Klopf \& Yu, 2007). It is a powerful tool to promote visiting advertisers' sites (Klopf \& Yu, 2007). One of the most popular examples of these ads is what Google offers (Klopf \& Yu, 2007). For example, typing 'laptop', on the Google search engine, will generate a list of website links, but the top picture has a sponsor of PPC ads (see Figure 4) (Klopf \& Yu, 2007). PPC might be the optimal option for UDSB because it will lead it to know who is interested in being part of UDSB (Klopf and Yu, 2007). In addition, PPC can also maintain interaction with customers because they will visit UDSB's site (Klopf \& Yu, 2007). UDSB must avoid PPC if the marketing budget is low (Klopf \& Yu, 2007).

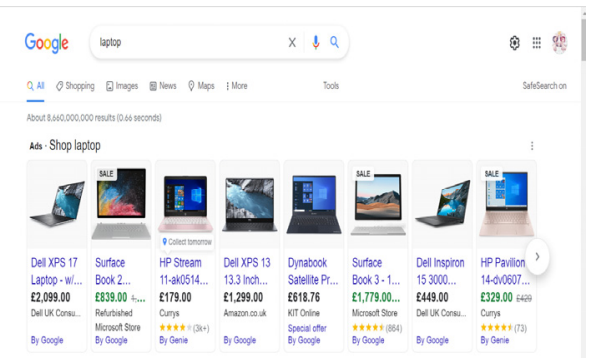

Figure 4. Digital Advertising is Pay Per Click (PPC) ads

Source: Google 2019.

Thirdly, a type of Digital Advertising is Cost Per Thousand Impressions (CPM) Bidding. It means that digital advertising will appear to a thousand users looking through the search engine for the word laptop, and this is a very useful method, for those with a limited marketing budget (Dickey and Lewis, 2012). Four type of Digital Advertising is video advertising: one of the best platforms that become famous via video advertising is YouTube (see Figure 5) (Dickey and Lewis, 2012). There are two types of video advertising, In-Stream Video Ads - these ads might apply before, during or after the original video play, and Out-Stream Video Ads which lead you to another video to watch the ad. The University of Dundee School of Business might use the latter type if their marketing budget is limited (Dickey and Lewis, 2012). 


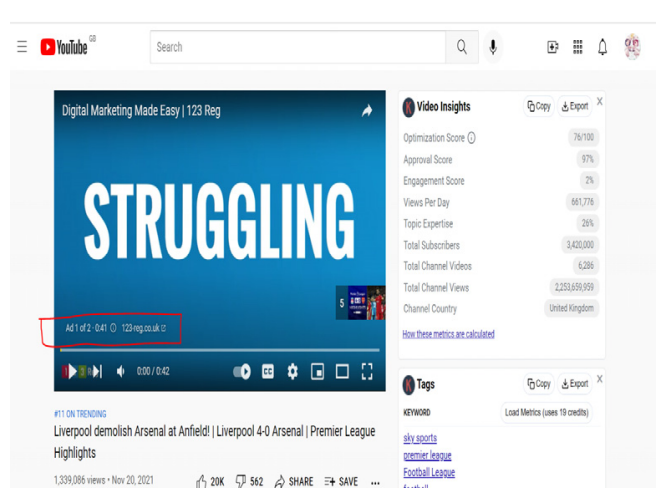

Figure 5. Digital Advertising is Cost Per Thousand Impressions (CPM)

Source: YouTube 2019.

Fourthly, a type of Digital Advertising is Retargeting, also known as remarketing, when the customers click to visit the advertising site (Google, 2019). This how retargeting ads work inserting a very small code on your site (this code could be referred to as a pixel). The pixel, or the code, is unobtrusive. The code won't affect the site's performance and visitors will not notice it. When visitors enter the site, the code will link to the users in the site. Later, when the visitors visit the Web, the code will let you retarget that customer and serve ads. Retargeting ads are served to only to people who have previously visited your site, for example, customers that add your products to their shopping cart but have not completed payment (see Figure 6) (Google, 2019).

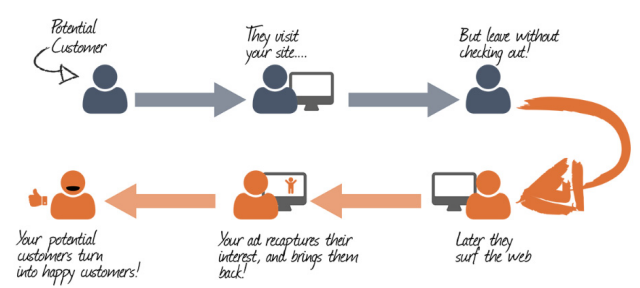

Figure 6. Retargeting ads

Source: Google, 2019.

\section{3. keys to create UDSB Text Ad}

- The title needs to have the best answer for the keywords that users might use as well as avoiding long sentences or phrases (see Figures 6\&7).
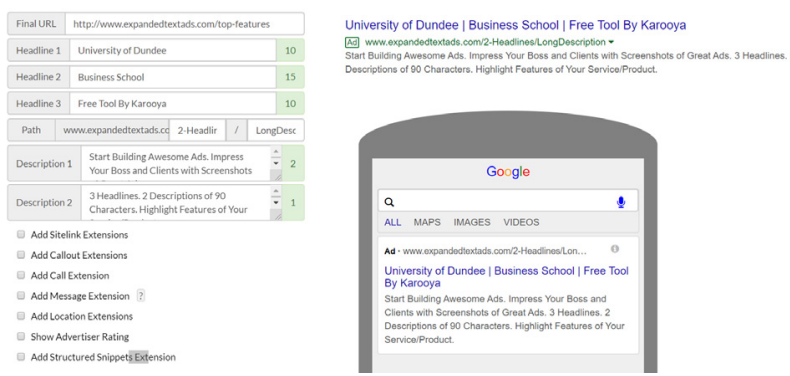

Figure 6. Suitable title (Source: Karooya, 2019). 


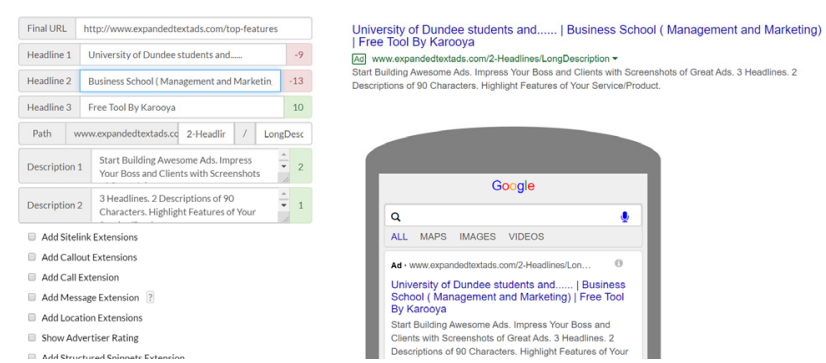

Figure 7. Long title

Source: Karooya, 2019.

- Adding a message, call and location to UDSB ads in order to attract different customers to contact UDSB. (see Figures 8)

- Adding advertiser ratings that could attract more customers and users by having five stars next to your ads.
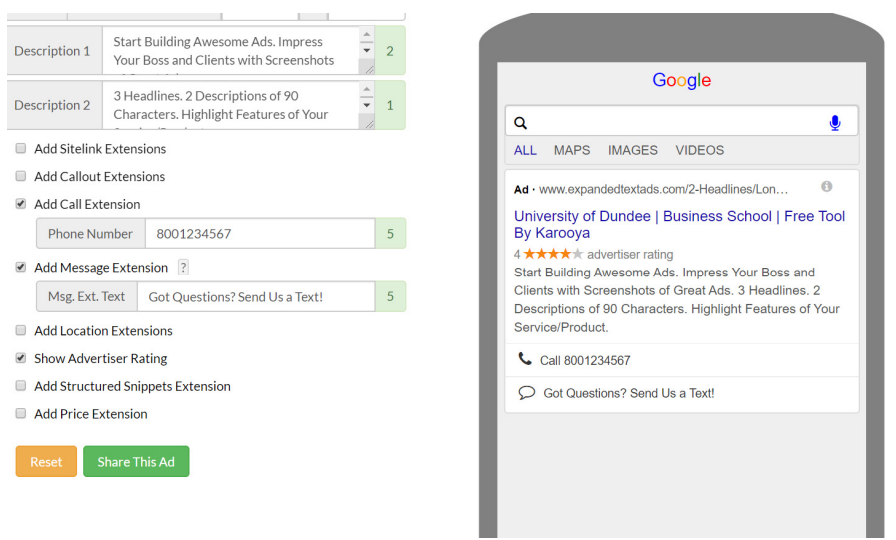

Figure 8. Adding messages, location, call and advertiser rate

Source: Karooya, 2019.

\subsection{What Makes Digital Advertising Campaigns Successful?}

First, outline your goals: who are you targeting and why. These questions are important before choosing which advertising to pick. The author believes that if the goal is to increase the awareness of the users about the websites then the most suitable digital advertising will be Pay Per Click (PPC) ads because it reaches a considerable number of users whereas if the goal is to show a particular product to particular customers then retargeting ad are the best choice (Dickey and Lewis, 2012).

Second, reach your audience: adding a promotion or page to your site will not automatically attract users to enter your website. Nowadays, social advertising offers targeting abilities that are extremely efficient to assist UDSB reach the right users. For example, Instagram can specify the audience based on very specific standards such as age, geographic location, connections, interests, career and education. Thus, this data can make Digital Advertising campaigns successful by providing control over a campaign that will help make it both valuable and successful (Dickey and Lewis, 2012).

\section{Digital Marketing Analytics}

\subsection{What are Digital Marketing Analytics?}

Digital marketing analytics is a tool for obtaining sufficient information about the behaviour of customers on different internet channels (Järvinen, 2015), because users or buyers may interact through it (Järvinen, 2015). In addition, it will probably lead to more revenue (Järvinen, 2015). Digital market analytics assist the development of marketing plans and strategies (Järvinen, 2015). It is data-based analysis, so it is possible to arrive at interval analyses between forecasts and reality (Järvinen, 2015). Digital Marketing analytics assist in understanding the client or user and how to attract them (Järvinen, 2015). There is a large number of Digital marketing analytics (Järvinen, 2015). The most relevant ones for UDSB are: 
- The number of visitors to the site is tracked via a code linked to the site, so that they can be reached through digital advertising (Flores, 2013).

- The number of customers staying at UDSB's website (Flores, 2013). The period of time customers stay on UDSB's website might lead the digital marketing team to understand the strengths of their website (Flores, 2013). In addition, the status of the client within the site has an important effect in that process (Flores, 2013). By staying at the UDSB site for a period of time, it is possible to know what features attract users' attention, by clicking on the items and then identifying users or customers (Flores, 2013. For example, one of the most famous sites using this method is Amazon (see Figure 9) (Flores, 2013).

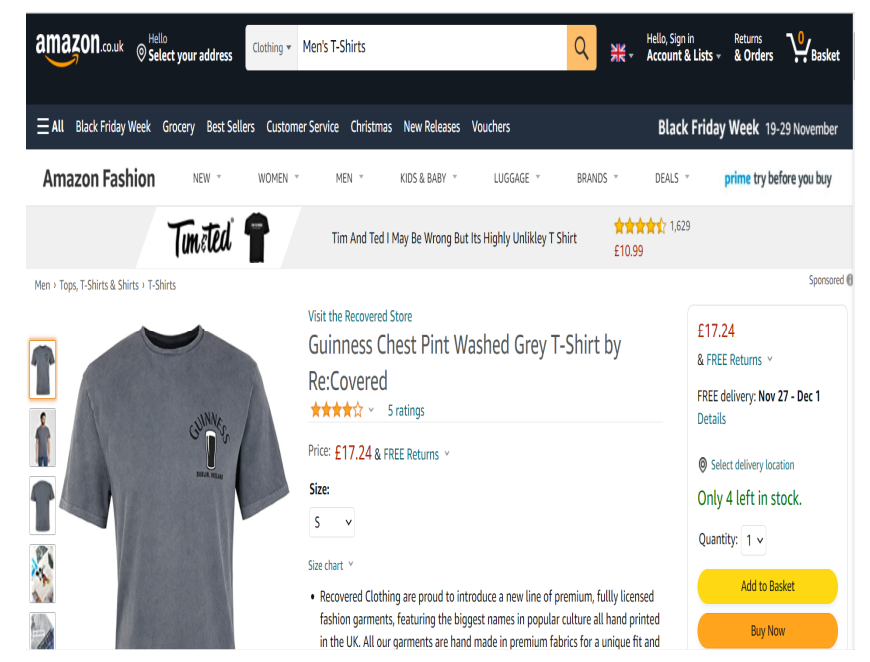

Figure 9. What goods attract users' attention

Source: Amazon 2019.

- Digital analytics for Email Marketing. These analytics are important for UDSB because they will lead to knowing how many users open an email or how many users click on the links (Flores, 2013). Thus, email analytics are significant to know how to attract your customer with your digital ads.

- The Click-Through Rate (CTR) is a way to determine the success of electronic advertising according to the number of viewers, or those who see UDSB's advertising and the people who actually clicked on the ad (Flores, 2013). It is vital to know the result because it will prove the success or failure of digital advertising. It might be that customers were not accurately defined or advertising content was not effective with users (Flores, 2013).

Getting all of this information from Digital Marketing analytics, and dividing it into small, manageable parts, can assist in the process of analysing the digital market (Flores, 2013). Moreover, it will allow UDSB to notice its strengths and weaknesses of its digital marketing approach (Flores, 2013).

\subsection{Two Main Keys of Digital Marketing Analysis}

There are a considerable number of means to make digital marketing successful (Stokes, 2011). Firstly, identify the goal clearly and identify the reason for collecting Digital Marketing analytics. Clear goals assist in knowing what categories of data you need in order to achieve that goal (Stokes, 2011). Goals differ in Digital marketing analysis, such as attracting new customers to UDSB's website or helping customers buy a particular product (Stokes, 2011). Secondly, user traffic on UDSB's site is likely to come from various search engines, by accessing UDSB directly through the URL, from other sites, from social networking sites or through paid advertising (Stokes, 2011). This data, when separated and analysed, will assist digital marketing to know where to focus, whether that be to increase user awareness of the brand or improve traffic (Stokes, 2011).

\section{Strategy and Planning of Digital Advertising Analytics for UDSB}

The strategy of Digital Advertising Analytics for UDSB can be divided into five parts:

1. The first step of the strategy is to start with a SWOT analysis, a useful step to understanding the strengths, weaknesses, opportunities and weaknesses of UDSB (Jackson, 2003). 
Table 1. SWOT analysis of UDSB (Jackson, 2003).

\begin{tabular}{|c|c|}
\hline THREATS & Opportunities \\
\hline $\begin{array}{l}\checkmark \quad \text { Use of digital advertising might incur significant } \\
\text { costs without getting any revenue from it. }\end{array}$ & $\begin{array}{l}\checkmark \text { UDSB could reduce the amount of data they need by using digital } \\
\text { advertising analytics on their customer traffic. }\end{array}$ \\
\hline $\begin{array}{l}\checkmark \text { Using digital advertising at the wrong time, or in } \\
\text { the wrong place, might lead to a negative reaction from } \\
\text { customers or users. }\end{array}$ & $\begin{array}{l}\checkmark \quad \text { UDSB has its own page on all the different platforms, such as social media } \\
\text { and YouTube. Linking all these platforms and using Digital Marketing Analysis } \\
\text { will lead to a focus on the customers' probability of staying longer and securing } \\
\text { their loyalty (see Figure 11). }\end{array}$ \\
\hline Weaknesses & Strengths \\
\hline $\begin{array}{l}\checkmark \text { There is no Digital Advertising on UDSB, such } \\
\text { as display advertising (also known as Native }\end{array}$ & UDSB can find its own data to analyse from its website. \\
\hline $\begin{array}{l}\text { Advertising). } \\
\checkmark \quad \text { Lacks the repeating of main words such as } \\
\text { 'School of Business'. }\end{array}$ & $\begin{array}{l}\checkmark \quad \text { UDSB has other school pages that can link all the pages to each other and } \\
\text { that will lead to an increase in the rank of the final search results on the search } \\
\text { engine (see Figure 10). }\end{array}$ \\
\hline
\end{tabular}
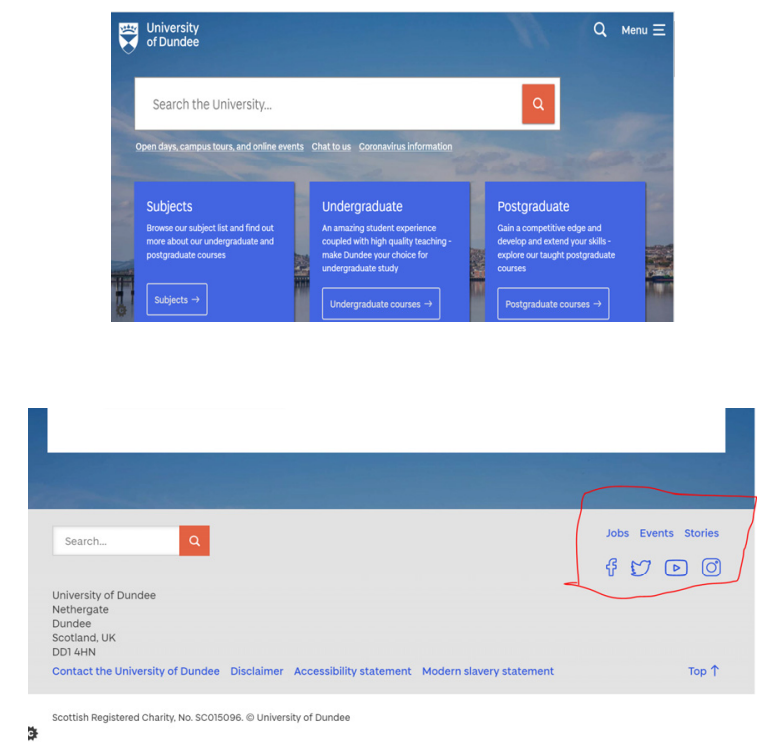

Figure 11. UDSB and social media

Source: The University of Dundee School of Business 2019.

2. The second step of Digital Advertising Analytics is to define the goal of Digital Advertising. Determining the goal of Digital Marketing - whenever the goal of marketing is identified and clear, what UDSB wants by using digital advertising is clearly identified. Determining whether the goal of marketing is the dissemination of the site, brand or raising the number of visitors to the site is known (Hemann, 2013).

As examples:

- An Unclear goal would be using digital advertising to get a higher number of visitors (Hemann, 2013). A goal that has no numbers is difficult to a) improve and $b$ ) find the weakness points.

A positive goal in digital marketing is that you divide a goal into short- and long-term aspects (Hemann, 2013). The goal of digital marketing is to get 1000 visitors in the first month, or the first three months, and 10,000 visitors by the end of the year. The reason behind this is that when short-term goals are not realized, UDSB might have a quick reaction, developing, or improving digital marketing (Hemann, 2013).

3. The third step of Digital Advertising Analytics is network display advertising. It is a way to display advertising on external sites (known as third-party websites) that share the same demographics, users or customers (Goldfarb \& Tucker, 2011). Moreover, UDSB might pay only for the first 1000 Impressions (CPM) 
(Goldfarb \& Tucker, 2011), in order to maintain the marketing budget (Goldfarb \& Tucker, 2011). This method leads to more budget control and UDSB will know how much this ad will cost (see Figure 12) (Goldfarb \& Tucker, 2011).

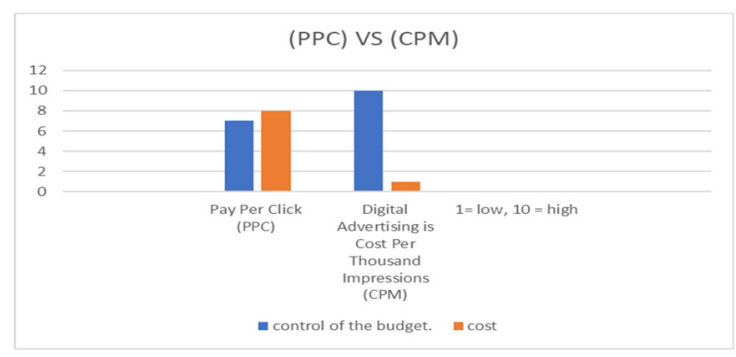

Figure 12. PPC VS CPM

Source: Goldfarb \& Tucker, 2011.

4. The four step of Digital Advertising Analytics is revenue from digital advertising (Hemann, 2013). Digital Advertising does not end with digital marketing analysis before the ad is displayed (Hemann, 2013). UDSB must not leave anything to chance in digital marketing (Hemann, 2013). Moreover, UDSB needs to keep up with the results of Digital Advertising and then develop, improve or even change it if necessary (Hemann, 2013).

5. The final Digital Advertising retargeting assists UDSB to reselect their visitors depend on the geographic location. By using digital advertising analytics UDSB can select a specific location, for example, "United States" and then pick one or more such as psychographic or behaviours to design the retargeting ad (see Figure 13) (Hemann, 2013).

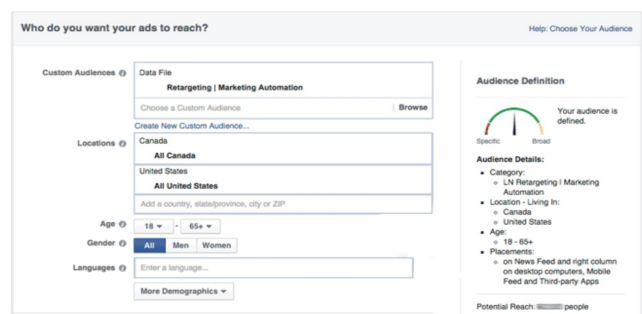

Figure 13. retargeting segmentation

Source: Goldfarb \& Tucker, 2011.

\section{Recommendation for strategy and planning of Digital Advertising Analytics for UDSB}

Table 2. Recommendation for strategy and planning of Digital Advertising Analytics for UDSB

\begin{tabular}{ll}
\hline Internal data & External data \\
\hline o All the data needed to do digital advertising analytics is & o Digital advertising requires accurate information to understand users \\
on UDSB's website and from that information UDSB will & or customers, across Google and other platforms. Therefore, users' and \\
probably use it to do the digital marketing analysis. In & $\begin{array}{l}\text { customers' information should be obtained from reliable and confidential } \\
\text { addition, free data is generated to help understand customers }\end{array}$ \\
sites. For example, the keyword tool might assist UDSB to understand \\
(Chaffey, 2010).
\end{tabular}

Source. Chaffey, 2010. 


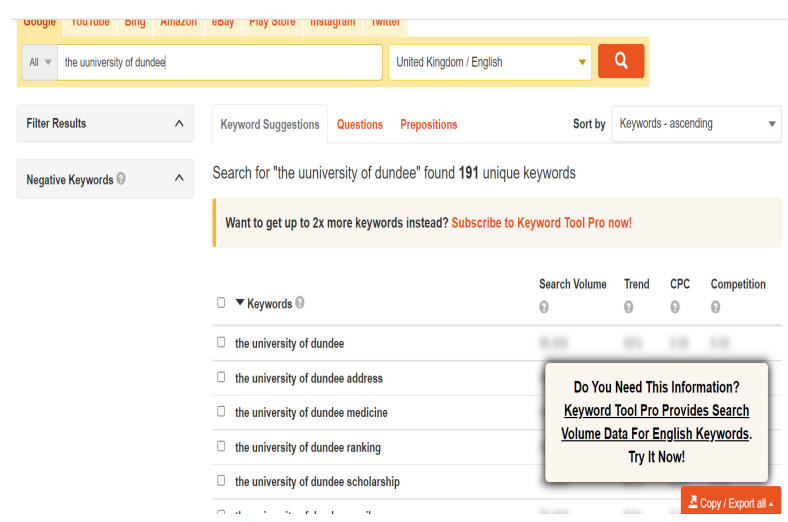

Figure 13. External data

Source. Keyword Tool 2019.

\subsection{Conclusion}

In sum, Search Engine Optimisation (SEO) is the most effective digital marketing technique for UDSB, but also the most challenging, for UDSB to reach a final decision without obtaining the required data and the purpose of advertising. This report has outlined the search marketing strategy for UDSB conversion degrees. However, this report has not explained the different platforms of search engines. This report has proposed five main ideas: Search Engine Optimisation (SEO), Digital Advertising, Digital Marketing Analytics, Strategy and Planning of Digital Advertising Analytics for UDSB, followed by some recommendations and a conclusion. Further research or reports could be done about UDSB in terms of social media advertising compared to digital advertising.

\section{References}

Amerland, D. (2013). Google Semantic Search: Search Engine Optimization (SEO) Techniques That Get Your Company More Traffic, Increase Brand Impact, and Amplify Your Online Presence. Que Publishing. USA.

Bao, S., Xue, G., Wu, X., Yu, Y., Fei, B., \& Su, Z. (2007). May. Optimizing web search using social annotations. In Proceedings of the 16th international conference on World Wide Web (pp. 501-510). ACM. https://doi.org/10.1145/1242572.1242640

Chaffey, D. (2010). Applying organisational capability models to assess the maturity of digital-marketing governance. Journal of Marketing Management, 26(3-4), 187-190.

Dickey, I. J., \& Lewis, W. F. (2012). An overview of digital media and advertising. In E-marketing: Concepts, methodologies, tools, and applications, IGI Global, USA.

Dover, D., \& Dafforn, E. (2011). Search engine optimization (SEO) secrets. Wiley publishing. Canada.

Flores, L. (2013). How to measure digital marketing: metrics for assessing impact and designing success. Springer. Palgrave Macmillan, London.

Go, E., \& CSD, K. K. (2006). Digital advertising method utilizing a cellular telephone display. U.S. Patent 7,010,293.

Goldfarb, A., \& Tucker, C. (2011). Online display advertising: Targeting and obtrusiveness. Marketing Science, 30(3), 389-404.

Google. (2019). Google Ads Help, Google. Retrieved from https://support.google.com/google-ads/answer/2453998?hl=en-GB

Gudivada, V. N., Rao, D., \& Paris, J. (2015). Understanding search-engine optimization. Computer, 48(10), 43-52. https://doi.org/10.1109/MC.2015.297

Gunjan, V. K., Kumari, M., Kumar, A., \& Rao, A. A. (2012). Search engine optimization with Google. International Journal of Computer Science Issues (IJCSI), 9(1), 206.

Hemann, C., \& Burbary, K. (2013). Digital marketing analytics. Making Sense of Consumer Data in a Digital World. Que Publishing, USA. 
Jackson, S. E., Joshi, A., \& Erhardt, N. L. (2003). Recent research on team and organizational diversity: SWOT analysis and implications. Journal of management, 29(6), 801-830. https://doi.org/10.1016/S0149-2063_03_00080-1

Järvinen, J., \& Karjaluoto, H. (2015). The use of Web analytics for digital marketing performance measurement. Industrial Marketing Management, 50, 117-127.

Karooya (2019). Expanded Text Ad Preview Tool, Karooya. v Retrieved from https://www.karooya.com/expanded-text-ad-preview-tool

Klopf, S., \& Yu, J., Steven, K. (2007). Digital advertising system. U.S. Patent Application 11/439,492.

Peter, J. P., Olson, J. C., \& Grunert, K. G. (1999). Consumer behaviour and marketing strategy. McGraw-Hill, London.

Seymour, T., Frantsvog, D., \& Kumar, S. (2011). History of search engines. International Journal of Management \& Information Systems (IJMIS), 15(4), 47-58. https://doi.org/10.19030/ijmis.v15i4.5799

Spais, G. (2010). Search Engine Optimization (SEO) as a dynamic online promotion technique: the implications of activity theory for promotion managers. Innovative Marketing, 6(1), pp.7-24.

Stokes, R. (2011). eMarketing: The essential guide to digital marketing. Quirk eMarketing, Canada.

Taylor, C.R., 2009. The six principles of digital advertising. International Journal of Advertising, 28(3), 411-418. https://doi.org/10.2501/S0265048709200679

\section{Copyrights}

Copyright for this article is retained by the author(s), with first publication rights granted to the journal.

This is an open-access article distributed under the terms and conditions of the Creative Commons Attribution license (http://creativecommons.org/licenses/by/4.0/). 